\title{
Study of Sea Surface Temperature (SST) and Sea Level Rise (SLR) Along Karachi Coast using Satellite Data, Pakistan
}

\author{
Talal Naseer ${ }^{1, *}$, Stefano Vignudelli ${ }^{2}$ and Arjumand Zaidi ${ }^{1}$ \\ ${ }^{1}$ United States Pakistan Center for Advanced Studies in Water, Mehran University of Engineering and \\ Technology, Jamshoro, Pakistan \\ ${ }^{2}$ Consiglio Nazionale delle Ricerche, Pisa Italy; stefano.vignudelli@pi.ibf.cnr.it \\ *Correspondence : talalnaseer15@gmail.com ; Tel : +92-333-780-5375
}

\begin{abstract}
The rising temperature due to climate change leads to glaciers melting, causing increased sea levels and sea surface temperatures (SST). The rising SST and glacier melting elevate sea levels around the globe. The rising sea level is hazardous for the coastal regions worldwide, and therefore, calls for continuous monitoring to manage this threat. Pakistan, with a coastline of $990 \mathrm{~km} \mathrm{long}$, is among those countries most vulnerable to sea-level rise (SLR). Around $10 \%$ of Pakistan's population lives near the coastal zones, which are most marginalized and dependent on fishing and small agricultural farms. An SLR of a few millimeters per year is a serious threat to Pakistan's coastal areas that can, directly and indirectly, cause land loss of low-lying areas and destruction of infrastructures, human settlements, agricultural lands, and coastal ecosystems, and other resources. The coastal communities of developing countries such as Pakistan, lacking essential resources, are the most disadvantageous and adversely affected people of the world due to these disasters. To overcome resources and capacity constraints, remote sensing (RS) and Geographic Information System (GIS) techniques can be employed to monitor coastal zones at larger extents. In this study, SLR and SST around the coast of Karachi have been investigated using multi-mission satellite radar altimetry (SRA) and MODIS Terra L3 SST product. The SRA is used to monitor sea levels using data from 1993 to 2018. Similarly, monthly SST data from 2000 to 2019 have been acquired to monitor SST trends. The rising sea levels and temperatures were estimated at $3.9 \mathrm{~mm} /$ year and 0.0138 ${ }^{\circ} \mathrm{C} /$ year, respectively. Different extrapolation techniques can further be utilized to predict the potential of SLR and SST in the study area for developing future coastal zone management plans.
\end{abstract}

Keywords: coastal zone management plans; GIS techniques; remote sensing; satellite radar altimetry; sea level rise; sea surface temperature.

\section{Introduction}

This study aims to explore the trend of sea-level rise (SLR) along the coast of Karachi, Pakistan using satellite radar altimetry (SRA) and tide gauge data. Soon, SLR is expected to adversely affect developing countries like Pakistan lacking infrastructure and resources and having heavily populated vulnerable coastal communities. Pakistan is included in one of those countries, which are most vulnerable to global warming and SLR. Though Pakistan is not a prime contributor to greenhouse gases but is already encountering the adverse impacts of changing climate. These effects include glaciers melting, long-term droughts, cyclones, flash floods, heatwaves, early summers, and warm winters. The rise in temperatures may cause SLR in Pakistan coastal areas due to heatwaves, glaciers melting, and seawater thermal expansions. The increase in sea levels may impose soil erosion threats, sea water intrusion, flooding and sinking of low-lying areas near the coastlines, and local population displacement. A rise of $1.1 \mathrm{~mm} /$ year has been observed in sea level at the Karachi coast [1].

In the early $90 \mathrm{~s}$, coastal areas' temperature had risen from 0.1 to $0.6^{\circ} \mathrm{C}$. Some studies show an increasing trend of $0.2{ }^{\circ} \mathrm{C}$ per decade on the shores of Pakistan. However, a higher SST rate was 
observed near the Karachi coast due to the rapid industrialization and higher air temperature [2]. The climate changes due to anthropogenic activities can significantly add additional hazards in our lives that may adversely affect highly populated and already vulnerable coastal cities. Therefore, to address this critical and attention-seeking issue, SLR monitoring along the coast was considered indispensable.

\subsection{Altimetry}

With a lack of resources, capacity, and infrastructure, it is impossible to monitor SLR and its impacts on Pakistan's coastal regions. It's strenuous to monitor or predict SLR and its implications with a $990 \mathrm{Km}$ long coastal line and a few partially working tide gauges. In such a scenario, remote sensing (RS) is the only way to fill this gap, in which satellite altimetry will help to a greater extent. Altimetry is a technique for measuring heights. The principle of the object-detection system with radio waves applies in the altimetry system where the distance between a satellite altimeter and the sea surface is calculated using the return period of a radar pulse and accurate satellite location data.

\section{Methodology}

\subsection{Study Area}

The study site is located on the Arabian Sea shoreline near Karachi, Sindh (Figure 1). Karachi is the largest city in Pakistan. Out of $990 \mathrm{~km}$ long coastline of Pakistan, the coastline of Sindh province is about $270 \mathrm{~km}$ long, comprising $100 \mathrm{~km}$ long Karachi coast with two largest seaports, Coast of Thatta from Korangi creek to India's border and Rann of Kutch (Badin to Tharparkar region). Karachi's coastline is situated between the Gharo Creek and the Hub River. Karachi is the seventh-largest city in the world with an estimated Gross Domestic Product (GDP) of $\$ 114$ billion, $42 \%$ of the country's total GDP [3], and, therefore, is known as the economic hub of Pakistan.

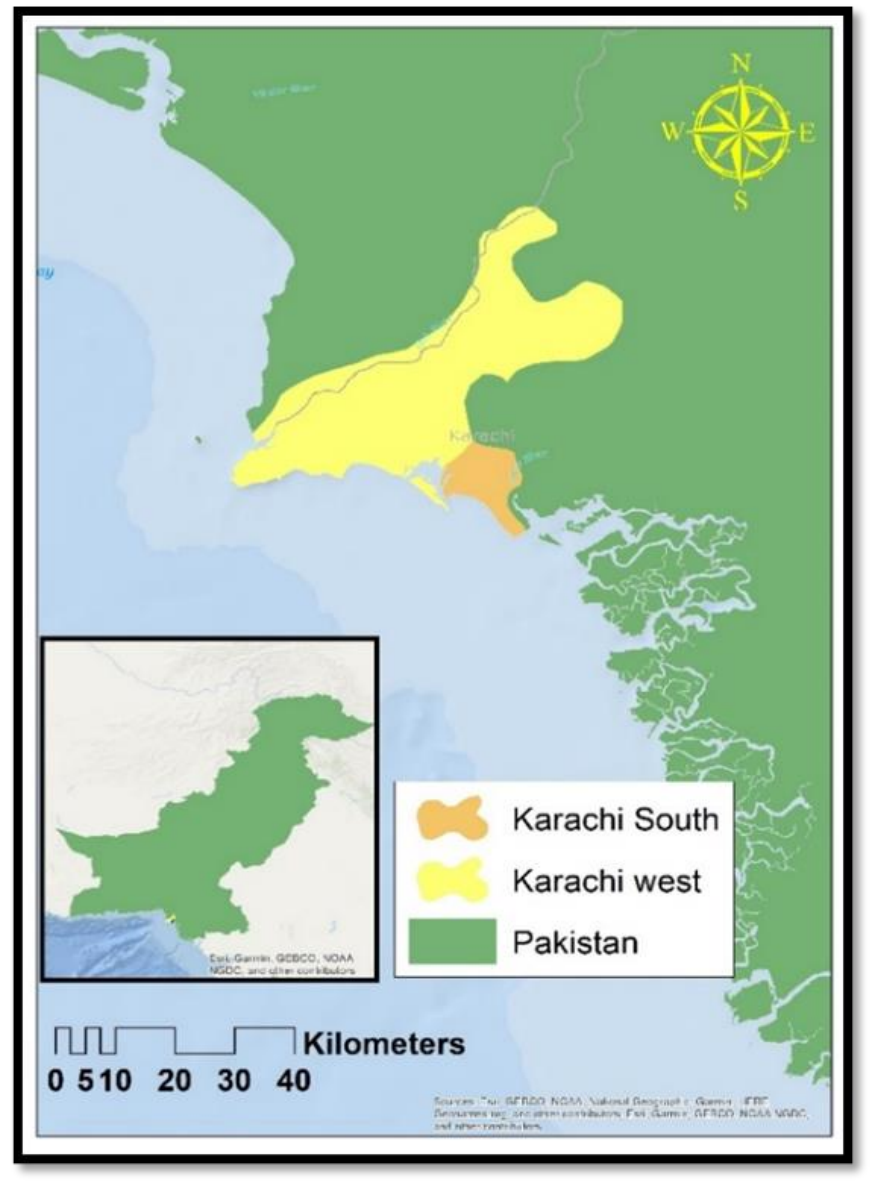

Figure 1. Study Area. 


\subsection{Data Analysis}

The methodology in Figure 2 correlates the study datasets. First, the data were collected from different sources. Tide gauge data were obtained from the University of Hawaii Sea Level Center (UHSLC). The data for SST was acquired from an online source. In this analysis, the MODIS Terra L3 SST Thermal Monthly $4 \mathrm{~km}$ Daytime data were used. The multi-mission altimetric data were obtained from the Jet Propulsion Lab's Physical Oceanography Distributed Active Archive Center (PODAAC).

Figure 3 shows the location of the tide gauge station nearest to the study area. Multi-mission satellite tracks are also plotted in Figure 3 in different colors representing the paths of Jason, Envisat (old and new orbits), and Sentinel A \& B satellites. The nearest PODAAC grid to the Karachi gauge station can be visualized in Figure 3.

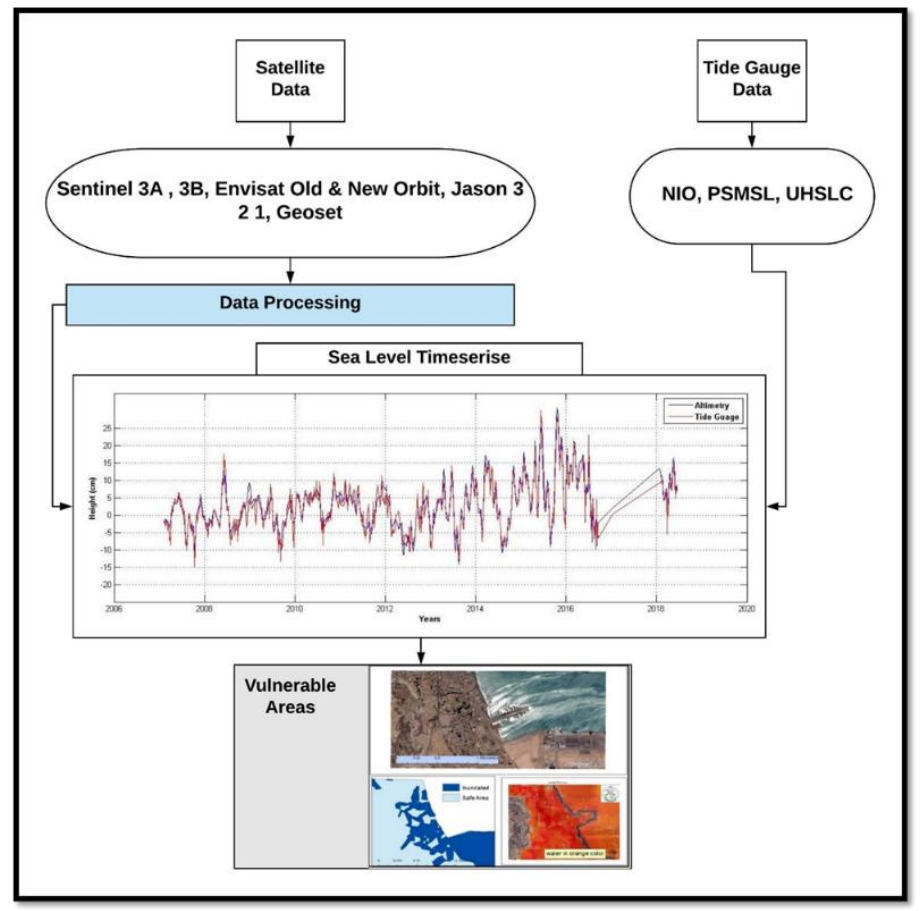

Figure 2. Methodological Framework.

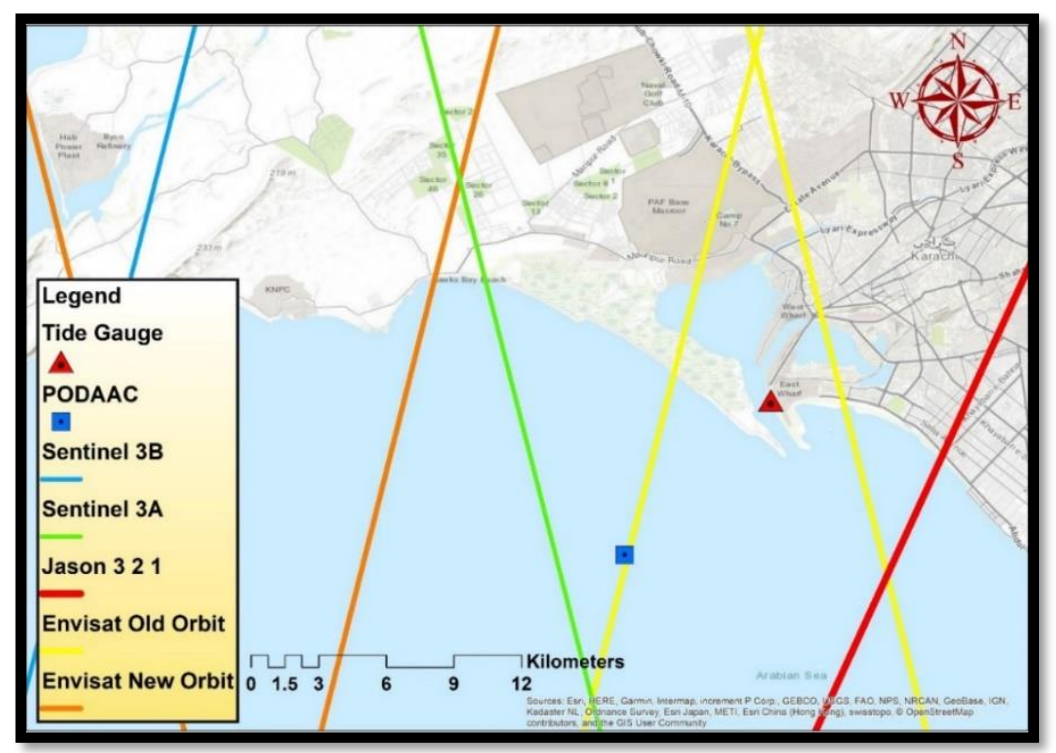

Figure 3. Tide gauge of Karachi, Pakistan and PODAAC grid with satellite tracks overlaid. 


\section{Results and Discussions}

The sea surface anomalies were derived from multi-mission altimetric and tide gauge data for Karachi. Both datasets show a decent agreement for the entire time series from Jan 06, 2007, to Apr 21, 2018 (gauge data for 2017 were missing). The results gave an $\mathrm{R}^{2}$ value of $0.8955, \mathrm{RMSE}=2.1 \mathrm{~cm}$, and a correlation of 0.94 , as shown in Figures 4 and 5.

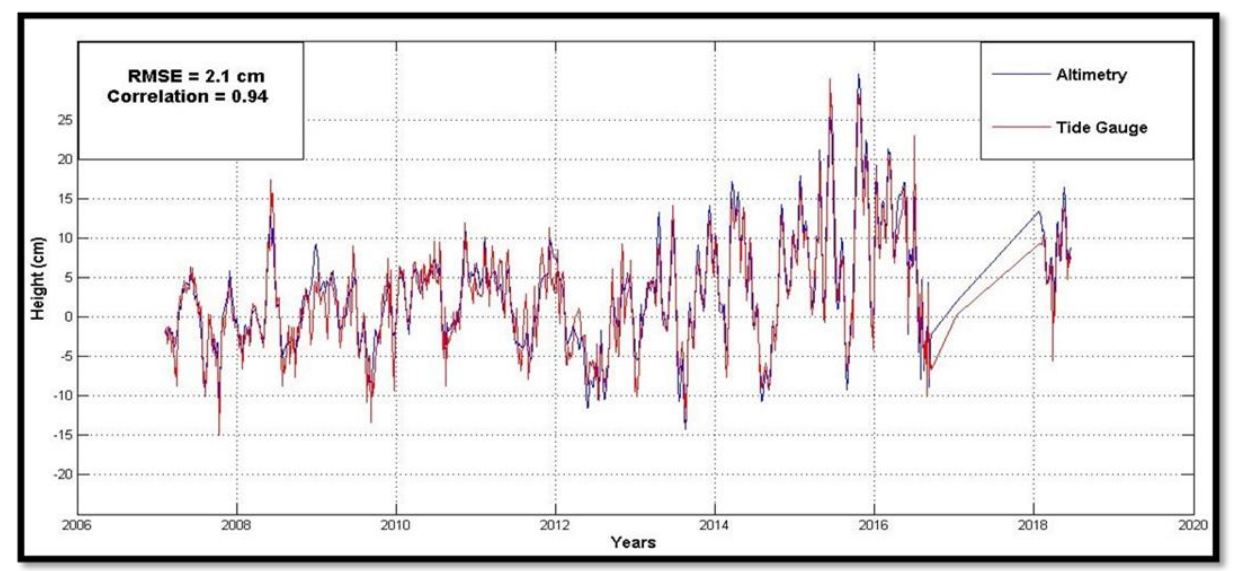

Figure 4. Comparison of altimetric and tide gauge data.

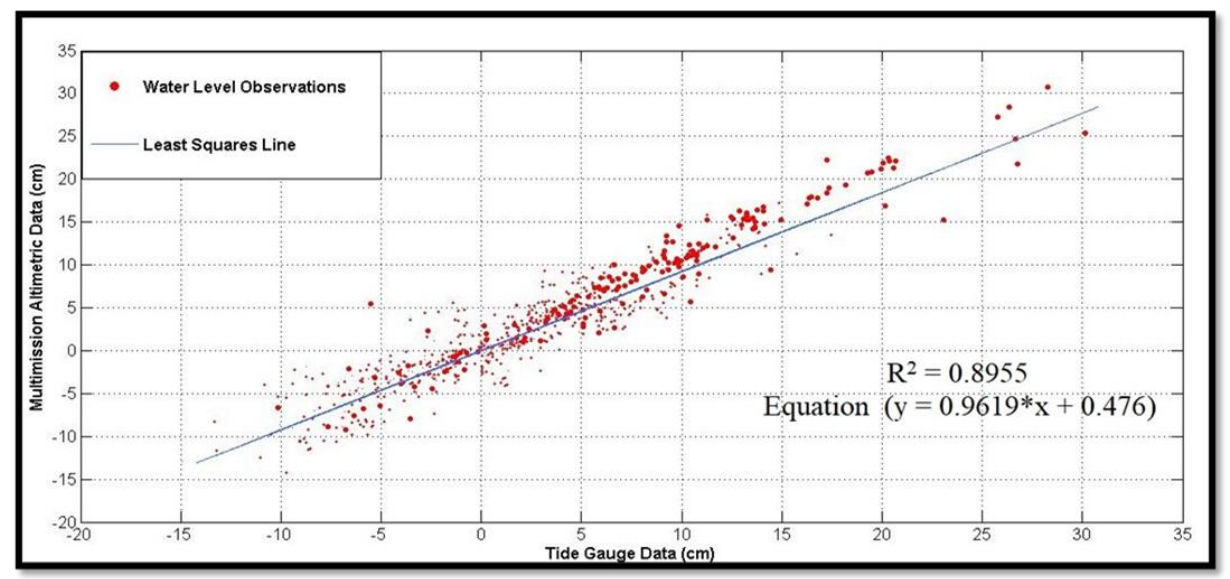

Figure 5. Scatter plot of altimetry and tide gauge data.

\subsection{Trend Analysis of SLR}

The linear trend analysis of multi-mission altimetric data of sea, surface anomalies show a rise of $3.9 \mathrm{~mm}$ /year for the available data from 1993 to 2018 as shown in Figure 6. Further, the multimission altimetric data is linearly extrapolated from 2019 to 2045 for Karachi using the linear regression method to forecast future values based on historical values with a $95 \%$ confidence level. It is speculated that a $15.62 \mathrm{~cm}$ gradual rise of sea level in the next 25 to 30 years will be observed at Karachi (Figure 7). 


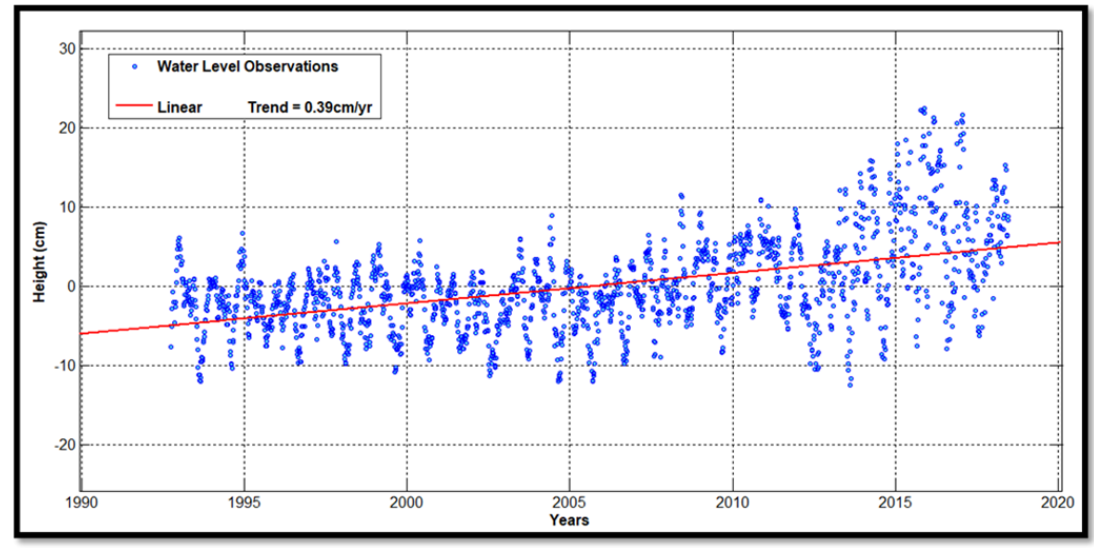

Figure 6. Trend analysis of altimetric data for sea surface heights.

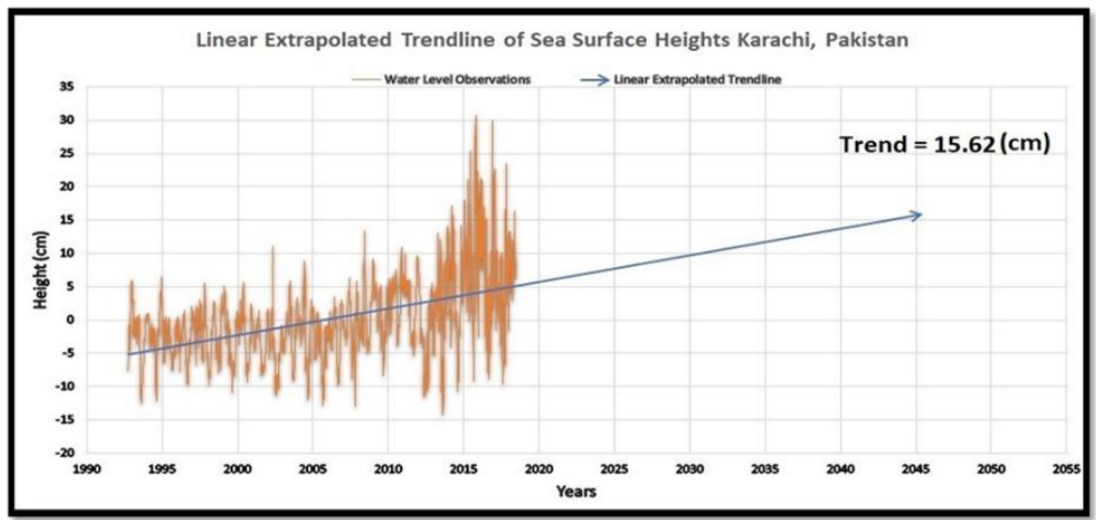

Figure 7. Extrapolation of the linear trend in sea level rise.

\subsection{Sea Surface Temperature (SST)}

The trend analysis of SST for Karachi, Pakistan, was performed using historical time-series data of the last 19 years from 2000 to 2019. It has been observed that SST has an insignificant rise of 0.0138 ${ }^{\circ} \mathrm{C} /$ year with a slightly increasing trend (Figure 8). The future SST values were forecasted with the linear regression line based on historical records, with a 95\% confidence level. The linearly predicted values for the next 25 years show a much higher trend with a $0.35{ }^{\circ} \mathrm{C}$ rise until 2045 (Figure 9). This rise may directly contribute to the rising sea level around the coast of Karachi. According to a study, the global SST is predicted to increase by $1.9^{\circ} \mathrm{C}$ by the end of the $21^{\text {st }}$ century, which will cause a global sea-level rise of $56 \mathrm{~cm}$ [4].

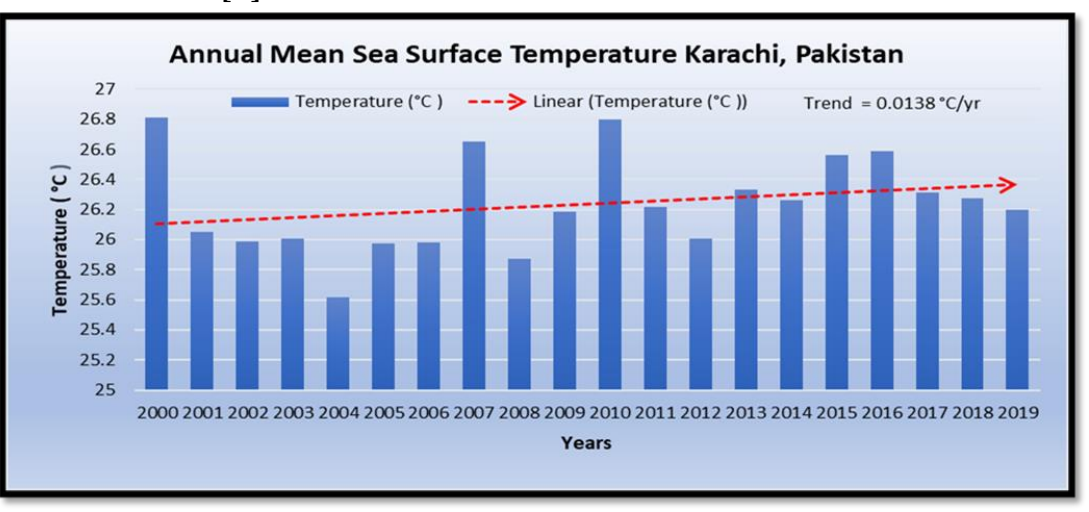

Figure 8. Trend analysis of sea surface temperature. 


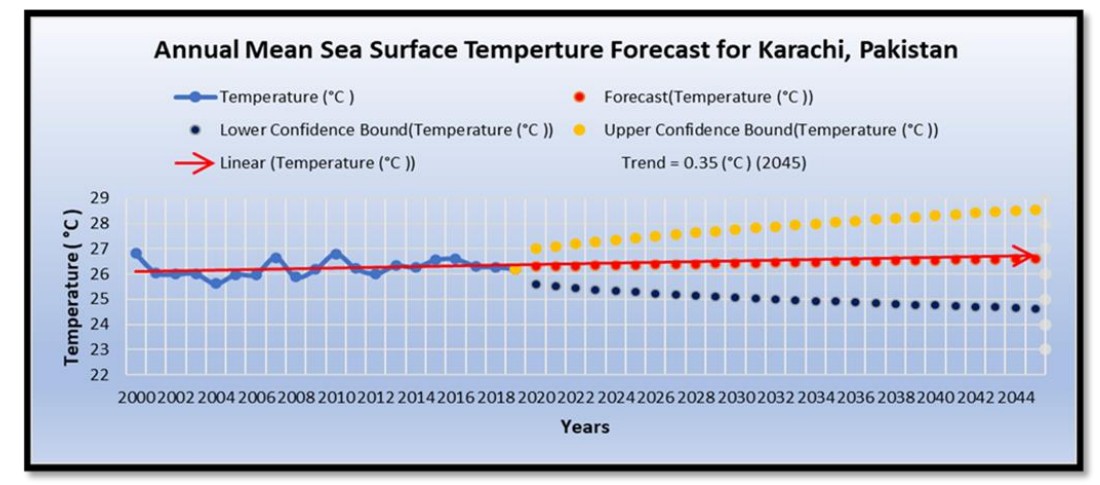

Figure 9. Sea surface temperature forecast.

\title{
4. Conclusions
}

The comparison of the multi-mission altimetric dataset with tide gauge data for Karachi leads to exciting findings. It can be concluded that overall, the datasets show a decent agreement with an $\mathrm{R}^{2}$ value of more than 0.80 . The trend analysis of altimetric data shows a sea-level rise of $3.9 \mathrm{~mm} / \mathrm{yr}$. On the other hand, the future predication of sea surface heights by linear extrapolation shows an increase of $150 \mathrm{~mm}$ in the next 25 years. According to different studies, it is estimated that a $1.1 \mathrm{~mm} /$ year rise in sea level is causing a horizontal beach loss of $110 \mathrm{~mm}$ per year or $1.1 \mathrm{~m}$ of beach loss in a decade [5]. Another study found that the Karachi coastline experienced $2.43 \pm 0.45 \mathrm{~m} / \mathrm{yr}$ of erosion [6]. Further, a similar trend analysis is carried out for SST by using the historical data, which shows a rise of $0.0138^{\circ} \mathrm{C}$ per year. Based on these historical values, the SST for the next 25 years is forecasted. The forecasted SST shows a higher value of $0.35{ }^{\circ} \mathrm{C}$ till 2045.

Acknowledgments: Special thanks to Ibrahim Zia, Research Officer (National Institute of Oceanography Karachi, Pakistan).

Author Contributions: T.N. analyzed the data and wrote the paper, T.N. and A.Z. contributed in materials/analysis tools, A.Z. reviewed the paper, S.V. reviewed the paper technically.

Conflicts of Interest: The authors declare no conflict of interest.

\author{
Abbreviations \\ The following abbreviations are used in this manuscript: \\ SST: Sea Surface Temperatures \\ SLR: Sea Level Rise \\ RS: Remote Sensing \\ SRA: Satellite Radar Altimetry \\ MSL: Mean Sea Level \\ GDP: Gross Domestic Product \\ UHSLC: University of Hawaii Sea Level Center \\ PODAAC: Jet Propulsion Lab's Physical Oceanography Distributed Active Archive Center \\ SSHA: Sea Surface Height Anomalies
}

\section{References}

1. Rabbani, Md \& Inam, Asif \& Tabrez, Ali \& Sayed, N \& Tabrez, S. (2008). THE IMPACT OF SEA LEVEL RISE ON PAKISTAN'S COASTAL ZONES- IN A CLIMATE CHANGE SCENARIO. 10.13140/2.1.2353.9203.

2. Khan, Tariq \& Ahmed Khan, Faisal \& Jilani, Rahmatullah. (2008). Sea surface temperature variability along the Pakistan coast and its relation to El Nino-southern oscillation. J.Basic Appl. Sci.. 4.

3. Jaffery, R. (2018). Impact of Climate Change on Karachi Maybe One of Pakistan's Biggest Threats. Inter Press Service News Agency. 
4. Aral, M.M.; Guan, J. Global Sea Surface Temperature and Sea Level Rise Estimation with Optimal Historical Time Lag Data. Water, 2016, 8, 519.

5. Tariq Masood Ali Khan, D. A. Razzaq, Qamar-Uz-Zaman Chaudhry, Dewan Abdul Quadir, Anwarul Kabir \& Majajul Alam Sarker (2002) Sea Level Variations and Geomorphological Changes in the Coastal Belt of Pakistan, Marine Geodesy, 25:1-2, 159-174, DOI: 10.1080/014904102753516804

6. Kanwal, S.; Ding, X.; Sajjad, M.; Abbas, S. Three Decades of Coastal Changes in Sindh, Pakistan (19892018): A Geospatial Assessment. Remote Sens. 2020, 12, 8.

(C) 2020 by the authors; licensee MDPI, Basel, Switzerland. This article is an open access article distributed under the terms and conditions of the Creative Commons by Attribution (CC-BY) license (http://creativecommons.org/licenses/by/4.0/). 